\title{
Multimodalidade e letramento: análise da propaganda Carrossel
}

\author{
Sônia Maria de Oliveira Pimenta \\ Denise Giarola Maia ${ }^{\star \star}$
}

\section{Resumo}

Neste artigo, fazemos uma análise dos recursos semióticos da propaganda Carrossel de uma campanha de inclusão social do portador da Síndrome de Down do Instituto MetaSocial. O vídeo foi divulgado na mídia televisiva em 1998, durante o horário comercial da Rede Globo. Para isso, fundamentamos nossa análise na Teoria Multimodal da Semiótica Social, mais especificamente nos trabalhos de Kress (2010), Kress e van Leeuwen (2001, 2006), van Leeuwen (2005, 2006, 2006b) e Street, Pahl e Rowsell (2011), através dos quais descrevemos e interpretamos os recursos semióticos utilizados na propaganda e a relação da imagem em movimento com outros modos com os quais ela interage para a criação da identidade do portador de Down como uma pessoa "normal" e que deve ser respeitada, ressaltando assim a necessidade cada vez mais urgente de um letramento multimodal para a compreensão e estudo dos mais diversos gêneros discursivos.

Palavras-chave: Semiótica social. Multimodalidade. Letramento. Propaganda.

\section{Introdução}

As tecnologias da comunicação, como a televisão, o DVD, o computador, e a internet, entre outros, permitiram não apenas o armazenamento e reprodução de informações, como também o uso de diversos recursos semióticos para a produção de mensagens. Desse modo, torna-se necessário um estudo que busque descrever o potencial semiótico de tais recursos para que os usuários possam dominar e interpretá-los mais criticamente; é o que tem sido realizado pelos pesquisadores da Semiótica Social.

* Docente Adjunto da Faculdade de Letras e Programa de Pós-Graduação em Estudos Linguísticos da Universidade Federal de Minas Gerais (UFMG). E-mail: soniapimenta1@gmail.com.

* Mestra em Letras pela Universidade Federal de São João del-Rei (UFSJ) e tutora no curso a distância de Letras/Português da Universidade Federal de Lavras (UFLA). E-mail: denisegiarolamaia@yahoo.com.br.

Data de submissão: fev. 2014 - Data de aceite: abr. 2014 http://dx.doi.org/10.5335/rdes.v10i1.4100 
Este artigo tem como objeto de estudo a propaganda intitulada Carrossel, divulgada em 1998, na mídia televisiva. Nosso interesse nesse objeto deve-se ao fato de esse gênero apresentar caracteristicamente um texto multimodal, no qual, o sentido é estabelecido na interação da imagem em movimento com a linguagem verbal e a trilha sonora, e, além disso, abordar o tema do preconceito em relação aos portadores da Síndrome de Down. Assim, o estudo desse objeto permite-nos discutir questões centrais apontadas pela abordagem Semiótica Social da multimodalidade e contribuir para o entendimento de como discursos são realizados em diferentes modos, ou pela combinação deles. Nosso objetivo é analisar os recursos semióticos utilizados no vídeo dessa propaganda, sobretudo aqueles do modo imagético, observando como eles se relacionam para construir o discurso de inclusão social, nesse gênero discursivo.

Para isso, dividimos este artigo em três partes. Na primeira, discutimos a abordagem Semiótica Social da multimodalidade. Na segunda, descrevemos os pressupostos para a análise da propaganda Carrossel, contextualizando esse objeto de estudo e apresentando os pressupostos teóricos da Gramática do Design Visual e o software ELAN, através do qual selecionamos os dados para a análise. Essa, finalmente, constitui o terceiro tópico deste artigo.

\section{Fundamentação teórica: multimodalidade e letramento}

No campo da Educação e das Ciências da Linguagem, o termo "letramento" é relativamente novo e representa uma nova forma de compreensão do saber ler e escrever em oposição ao termo "alfabetização", que remete à habilidade mecânica de codificar/decodificar.

Dizemos que uma pessoa é "letrada" quando ela vive na condição de quem sabe (ou aprende) ler e escrever em diferentes eventos e práticas sociais. Entende-se, com isso, que o letramento é múltiplo, pois, fazemos diferentes usos sociais da escrita. Além disso, o letramento implica que uma pessoa pode ser analfabeta, mas letrada. Nesse caso, ela não sabe ler nem escrever, mas, vive e participa de um ambiente no qual a leitura e a escrita estão presentes, por exemplo, ela dita cartas para outros escreverem, ela ouve textos que outros leem para ela (cf. SOARES, 1998).

Desse modo, o letramento indica a inserção e a participação do indivíduo no mundo da escrita como forma de participação na vida em sociedade e, portanto, corresponde a um "conjunto de atividades sociais que envolvem a língua escrita, e de exigências sociais de uso da língua escrita" (SOARES, 1998, p. 66). A escola é vista, nesse contexto, como uma agência que desenvolve um tipo de letramento acadêmico, em outras palavras, ela é apenas uma das agências que promovem o letramento. 
Nossa sociedade é composta por diversas esferas: escolar, literário-artística, científica, publicitária, religiosa, jurídica, política, econômica entre outras, em que determinadas práticas discursivas são realizadas pelo homem. Dentro da esfera familiar, por exemplo, cozinhar é uma prática social que apesar de parecer mais uma atividade física envolve também certas práticas discursivas, tais como receitas, listas de compra e cardápios, que são considerados gêneros discursivos. Assim, nossas práticas sociais (ações e interações sociais) são geradoras de inúmeros gêneros que refletem nossos propósitos comunicativos, e que organizam e governam nossas ações (cf. BAKTHIN, 2000). No exemplo supracitado, a receita ensina como se deve cozinhar e quais são os ingredientes que a pessoa precisa comprar para preparar um determinado prato.

As práticas de letramento, no âmbito escolar, devem então estar pautadas no estudo dos mais variados gêneros textuais, os quais o sujeito (aluno) já está familiarizado e com aqueles os quais desconhece, permitindo assim sua inserção nas esferas de maior poder na sociedade.

Porém, essa concepção de letramento é relativamente limitada, porque a comunicação e a representação não se realizam apenas e exclusivamente por meio da linguagem verbal. Nunca foi assim e, especialmente, nos dias de hoje, com a globalização e o advento de novas tecnologias, as pessoas comunicam-se e representam o mundo, através de uma complexa relação intersemiótica, ou seja, vários modos são envolvidos em um evento comunicativo e todos os modos combinam para representar o sentido de uma mensagem. Por isso, Street, Pahl e Rowsell (2011) afirmam que é necessário ampliar a noção de letramento, incorporando-a em uma perspectiva multimodal.

Os gêneros discursivos são definidos pela sua função, em termos do que fazem, ou seja, são modelos de ação comunicativa e de estratégias e procedimentos para atender a certos propósitos comunicativos. Em relação à análise genérica, van Leeuwen (2005) diz que essa precisa ser modificada quando nós a transferimos do domínio "monomodal", textos lineares, para o multimodal, textos não lineares. Por texto não linear, o autor considera aqueles que têm um primeiro plano visual, não apenas o uso de imagens, mas toda a composição, tipografia e cor; e que permitem múltiplas formas de leitura, independentemente de ser ativada através de tecnologia (pensando aqui nos gêneros fixados em um suporte virtual), ou não. Por exemplo, ao lermos uma notícia, dependendo da disposição dos elementos no layout, bem como seu tamanho, cor etc., podemos, primeiramente, olhar uma fotografia e, em seguida, o título, e, por último, o texto verbal.

De acordo com van Leeuwen (2005), o propósito do gênero é desenvolvido em um texto em diversas etapas, que podem ser realizadas por um modo semiótico específico, dependendo do local de circulação e de fatores culturais, ou 
por diferentes modos simultaneamente. Voltando ao exemplo da receita, esta pode trazer a imagem de um prato para "abrir o apetite" do leitor e persuadi-lo a experimentar. A relação entre os modos dentro de uma etapa pode ser elaborativa ou extensiva. Por elaboração, o autor entende como a atualização de um conteúdo realizado em um modo por outro modo, seja para exemplificar, esclarecer, resumir, o que corresponderia à noção de ancoragem. Na ancoragem, tem-se, por exemplo, o verbal especificando o sentido da imagem, uma vez que esta, em muitos casos, é polissêmica, embora o oposto também seja possível (BARTHES, $1977^{1}$ apud KRESS; van LEEWEN, 2006). Já por extensão, entende como um modo adicionando algo novo (KRESS; van LEEUWEN, 2006).

No sistema educacional brasileiro, os Parâmetros Curriculares Nacionais (PCN's) de Língua Portuguesa, por exemplo, propõem que sejam trabalhadas capacidades de leitura de "outras linguagens". Em relação aos "signos não verbais", o documento Orientações Pedagógica de Língua Portuguesa do Ensino Médio comenta que:

Nas sociedades pós-modernas, a maioria das pessoas passa grande parte do tempo frente à tela de TV, de computador e de outras mídias. Encontra-se cercado de ilustrações, de cores, de gráficos e de tabelas, ou seja, vive cercado de uma paisagem semiótica, em que o que prevalece é muito mais o não verbal do que o verbal propriamente dito no desenvolvimento dos processos de recepção de mensagens visuais, a Semiótica Social surge como uma ciência que procura analisar os signos que circulam na sociedade. Vivemos cercados deles e cada um tem sua relevância e seu significado produzido pela cultura. [...] Essa profusão de signos não-verbais e a exigência da relação entre esses signos e os verbais, fez surgir o conceito de analfabeto visual, ou seja, da condição daquele que lê o código verbal, mas não consegue dominar estratégias de compreensão e de relação entre o verbal e o não-verbal (BRASIL, 2009).

Como observamos na citação, infelizmente, ainda não ocorre efetivamente no âmbito escolar a prática desse letramento multimodal. Embora o livro didático busque adequar-se às exigências dessas propostas curriculares, incorporando textos dos mais variados gêneros híbridos, como tirinhas, charges, publicidades, nos quais vemos com mais facilidade a relação intersemiótica, as atividades desses materiais priorizam a análise do modo escrito, e pouco, ou muito superficialmente, exploram aspectos dos outros modos, como a imagem, a cor, a tipografia.

Além disso, como comentam Kress e van Leeuwen (2006), nos anos iniciais, os livros didáticos são cheios de imagens e os alunos são motivados a ilustrarem suas atividades, contudo, à medida que os anos escolares avançam, a tendência é as imagens desaparecerem dos materiais didáticos e os alunos não serem encorajados a aperfeiçoarem suas habilidades de utilizar diferentes formas de comunicação e representação.

Nas considerações de sua monografia, na qual analisou a edição da prova do Enem 2009, que consiste em um sistema de avaliação em larga escala, cujo objetivo é avaliar o desempenho dos estudantes no final do ensino médio, Severo 
(2010) observou, quanto ao letramento multimodal, que

[...] há uma defasagem importante em relação ao desenvolvimento das habilidades necessárias para a leitura de textos multimodais, em que entram em jogo elementos não-verbais. Enquanto a prova apresenta questões que exploram esses recursos, as escolas continuam trabalhando a leitura de modo tradicional, apoiada no texto escrito, na maior parte do tempo (SEVERO, 2010, p. 42).

Esse letramento é ainda dificultado pelo fato de as disciplinas teóricas e a crítica especializada, que se desenvolveram para falar de cada modo, tornaram-se igualmente monomodal, por exemplo, a linguística preocupa-se com a linguagem verbal, a musicologia com a música, a história da arte com a arte, cada uma com seu método, seu vocabulário técnico, suas suposições (KRESS; VAN LEEUWEN, 2001).

Por isso, van Leeuwen (2005, 2006a, 2006b) e Kress (2010) assumem a posição de que é preciso uma teoria mais ampla, que traga todos os modos de fazer sentido juntos sob o mesmo campo teórico, como parte de um único campo. Essa teoria é a multimodalidade.

Contudo, para Kress e van Leeuwen (2001) e van Leeuwen (2005, 2006a), isso não será feito sem primeiro explorar separadamente o potencial comunicativo dos diferentes recursos semióticos envolvidos nos textos, para posteriormente encontrar conceitos funcionais, isto é, conceitos ou princípios multimodais que descrevem uma função de comunicação particular, e que serão aplicados a todos os modos semióticos que desenvolveram recursos para realizá-la, como, por exemplo, a saliência e a moldura que, como falaremos mais adiante, no subtópico 2.3 , são realizadas através de vários modos (imagem, tipografia, cor) e, dentro de cada um desses, de forma diferente.

Mas, então, o que vem a ser essa teoria da multimodalidade? Kress e van Leeuwen definem multimodalidade como

[...] o uso de vários modos semióticos no design de um produto semiótico ou evento, juntamente com a maneira particular em que estes modos são combinados - eles podem, por exemplo, reforçar-se mutuamente (dizer a mesma coisa de formas diferentes), desempenhar papéis complementares ${ }^{2}$ (2001, p. 20).

$\mathrm{E}$, nesse sentido, Jewitt diz que a

[...] multimodalidade descreve abordagens que entendem a comunicação e representação como sendo mais que a linguagem verbal, e que atende a toda gama de formas comunicacionais que as pessoas usam - imagem, gestos, olhar, postura, e assim por diante - e as relações entre $\operatorname{elas}^{3}$ (2011, p. 14).

Há uma variedade de disciplinas e perspectivas teóricas que devem ser usadas para explorar diferentes aspectos da paisagem multimodal, no entanto, o termo multimodalidade, ao qual nos referimos, está, neste artigo, fortemente ligado à Semiótica Social. O ponto inicial para uma análise semiótica social da multimodalidade foram os trabalhos de Halliday.

Halliday e Matthiessen definem texto como "[...] qualquer instância de linguagem, em qualquer meio, que produz sentido a alguém que conhece a linguagem"4 (2004, p. 3). Apesar de tratarem do texto verbal, essa é uma noção que explora 
a questão semântica e, por extensão, é aplicada a outras linguagens.

Para esses dois autores, a linguagem é multifuncional, ou seja, é responsável por três metafunções: (i) interpessoal, pois, através da linguagem atuamos nas relações sociais, interagimos com as pessoas ao nosso redor. É também através da linguagem que nos informamos ou questionamos algo, damos ordem ou fazemos uma oferta, e expressamos nossa apreciação ou atitude a respeito do que nos é destinado e do que estamos falando; (ii) ideacional, porque, quando usamos a linguagem damos sentido às nossas experiências. Não há nenhuma faceta da experiência humana que não possa ser transformada em sentido. $\mathrm{Na}$ oração, ${ }^{5}$ são representados participantes, processos (algum feito, acontecimento, dito, entre outros) e circunstâncias; e (iii) textual, responsável pelo sistema de informação e de organização da mensagem.

Posteriormente, Kress e van Leeuwen (2006) observaram como essas metafunções são realizadas visualmente, aplicando-as na análise de imagens. Tal trabalho referente à comunicação visual, segundo Jewit,

[...] abriu as portas para a multimodalidade e lançou as bases para o alargamento e adaptação da semiótica social através de uma variedade de $\operatorname{modos}^{6}$ (JEWIT 2011, p. 29).

A multimodalidade na perspectiva da Semiótica Social não é uma teoria acabada, pelo contrário, as discussões em torno desse fenômeno são recentes e estão abertas. Uma consequência disso é que as ferramentas teóricas e metodo- lógicas ainda estão sendo desenvolvidas. Por outro lado, cabe apresentar alguns conceitos chave para a multimodalidade: modo, recursos semióticos, discurso, design, estilo, estética e ética.

De acordo com Kress (2011), modo é uma forma socialmente e culturalmente determinada que oferece recursos para criar sentidos. São exemplos de modos, a imagem, a escrita, a música, o gesto e a fala, entre outros. Cada modo possui seu conjunto de recursos semióticos, que van Leeuwen entende como

[...] as ações e os artefatos que usamos para nos comunicar, sejam eles produzidos fisiologicamente - com nosso aparelho vocal, com os músculos que usamos para criar expressões faciais e gestos, etc. - ou por meio de tecnologias - com caneta, tinta e papel; com hardware e software de computador, com tecidos, tesouras e máquinas de costura, etc ${ }^{7}$ (LEEUWEN, 2006a, p. 3).

Recursos são vistos, portanto, como significantes, isto é, formas observáveis, que tenham sido delineados em um contexto social e cultural e que possuem um potencial semiótico constituído pelos usos passados, os quais são conhecidos dos usuários; ou pelos usos que poderiam vir a ser descobertos pelos usuários com base em suas necessidades e interesses. Van Leeuwen (2006a) apresenta-nos um exemplo interessante de recursos, o jeito de andar. Observa-se que as pessoas não andam de formas iguais, homens e mulheres andam diferentemente, certas instituições como o exército e a moda desenvolveram seus próprios jeitos especiais e cerimonias de andar. Através do modo como andamos, expressamos quem 
somos, o que estamos fazendo e como queremos nos relacionar com os outros. Além disso, diferentes modos de andar podem seduzir, impressionar, ameaçar.

Nessa perspectiva, recursos semióticos são motivados, isto é, a relação entre forma e sentido baseia-se nos interesses do produtor, e, portanto, são fluídos, dinâmicos e conectados ao contexto social de uso. Importante ressaltar que as pessoas expressam sentidos através da seleção que fazem dos recursos semióticos que consideram mais aptos e plausíveis para a comunicação, sendo essas escolhas sempre políticas. Kress (2010) denomina como estilo, então, essa série de escolhas feita no design da mensagem. Para o autor, a estética corresponde à política do estilo, ou seja, trata-se das variadas formas relacionadas às escolhas e suas composições. Enquanto que a ética estaria relacionada à política do valor $\mathrm{e}$ da avaliação, isto é, àquilo que consideramos digno de destaque e importância.

Em relação ao discurso, este, muitas vezes, está associado à linguagem verbal, no entanto, sua existência independe do modo ou do design, isto é, pode ser realizado em diferentes maneiras. Kress e van Leeuwen (2001) entendem discurso como conhecimentos construídos socialmente a respeito de algum aspecto da realidade.

Por fim, design refere-se aos usos dos recursos semióticos, em todos os modos semióticos e combinações desses. Também são meios de realizar discursos no contexto de uma situação comunicativa. É importante não confundir design com produção, uma vez que o primeiro está relacionado à criação, enquanto o último diz respeito à organização da expressão ou do meio de execução do que foi elaborado pelo design.

\section{Procedimentos metodológicos para a análise do texto multimodal}

\section{As propagandas do Instituto MetaSocial}

Em meados da década de 1990, é criado o Instituto MetaSocial, uma instituição sem fins lucrativos, que, em parceria com outras instituições, desenvolveu uma campanha na mídia televisiva, com o propósito de promover a inclusão das pessoas portadoras da Síndrome de Down, através de algumas propagandas.

O termo propaganda é utilizado para designar o gênero que tem como propósito divulgar uma ideia, buscando a adesão de um determinado público. Conforme Sant'Anna (1998, p. 75), esse termo refere-se à "propagação de doutrinas religiosas ou princípios políticos de algum partido". Desse modo, a propaganda está mais relacionada a objetivos políticos que comerciais, como é o caso da publicidade, e pode tanto manter o status quo quanto implantar mudanças sociais na sociedade.

A propaganda pode circular em várias mídias (televisão, rádio, jornal, revista e computador) e suportes (papel, internet, cartaz, outdoors). Dependendo da 
mídia e suporte em que circula, o gênero sofre algumas modificações em sua configuração. A propaganda televisiva, por exemplo, contém um texto mais dinâmico, isto é, curto, com imagens em movimento, um fundo sonoro, tal como são as propagandas do Instituto MetaSocial, que possuem curta duração, em média de trinta segundos a dois minutos, e são transmitidas durante o horário comercial da rede de televisão aberta, Rede Globo.

A proposta dessas propagandas, de acordo com o site do Instituto, é "mostrar de forma positiva, alegre e colorida as potencialidades de todas as pessoas, independentemente de suas limitações" e conscientizar a sociedade de que "todas as pessoas possuem o mesmo valor humano e, por isso, merecem ser tratadas com respeito e dignidade" .

A primeira, intitulada Pianista, foi transmitida em 1996. Dois anos depois, foi ao ar Carrossel, que ficou popularmente conhecido como "Carlinhos", nome do protagonista. Esta propaganda, na época, teve grande repercussão e recebeu diversas premiações, como o Globo de Ouro, o Bronze no Festival Internacional de Nova York e o Leão de Bronze no Festival de Cannes, na França. ${ }^{9}$ Em 2002, foi a vez de Garçonete. No ano seguinte, a agência Giovani+Draftfcb tornou-se parceira do Instituto MetaSocial, juntas criaram o slogan "ser diferente é normal" e lançaram várias propagandas para essa campanha de inclusão social, como Adolescente, em 2003, e depois, Diferen- ças, em 2005, Menina Azul, em 2007, e Menina Diferente, em 2011. Todos os vídeos dessas propagandas estão disponíveis no site do Instituto (http://www. metasocial.org.br).

Para este artigo, faremos uma análise apenas do vídeo da propaganda Carrossel, no entanto, pretendemos, em outro momento, analisaros outros vídeos, uma vez que esses exploram diversos recursos semióticos para construção do discurso do preconceito e da diferença.

A gramática do design visual (GDV)

Analisaremos os recursos utilizados, especialmente, do modo imagético para a construção do discurso de inclusão social no vídeo da campanha Carrossel do Instituto MetaSocial. Para isso, faremos uso das categorias propostas por Kress e van Leeuwen (2006) para a análise de imagens.

Conforme comentamos no tópico anterior, as três metafunções da linguagem verbal, descritas por Halliday e Matthiessen (2004), podem ser igualmente realizadas por outros modos semióticos. Em Reading Imagens, Kress e van Leeuwen (2006) descrevem os recursos disponíveis no modo imagético para desempenhar essas metafunções.

Para os autores, a metafunção ideacional é a habilidade do sistema semiótico em representar objetos, ou participantes, e sua relação com o mundo. Existem dois tipos de participantes envolvidos no ato semiótico, o participante interativo, 
que diz respeito às pessoas reais - tanto aquela que produz quanto aquela que consome -, e os participantes representados, que são as pessoas e objetos representados na imagem. Esses últimos desempenham funções semióticas, isto é, podem ser ator, quando partir deles partem os vetores, e meta, quando o vetor aponta para eles.

Vetores são aquilo que linguisticamente definimos como "verbos". Nas imagens, eles são linhas visíveis ou imaginárias formados pelos corpos, ou membros, ou ferramentas em ação, e que indicam processos, os quais são de dois tipos: narrativos ou conceptuais.

Quando o participante está conectado por um vetor, ele é representado como fazendo algo para alguém. Esse tipo de padrão vetorial é denominado por Kress e van Leeuwen (2006) como narrativo. Cinco diferentes tipos de processos narrativos podem ser distinguidos com base no tipo de vetor e no número e tipo de participante envolvido. $\mathrm{O}$ primeiro deles é o processo de ação, os acontecimentos do mundo material são descritos ou apresentados. Seus participantes são o ator, participante de quem o vetor parte, e o alvo, participante que é atingindo pelo vetor. Esse tipo de estrutura corresponde aos processos materiais e comportamentais, no modo verbal, e dois tipos são diferenciados: (i) não transacional: a ação não é feita para alguém ou algo, ela corresponde ao verbo intransitivo. Assim, possui apenas um participante, o ator; (ii) transacional: a ação é feita para alguém ou algo. Nesse caso, corresponde aos verbos transitivos. Tem-se pelo menos dois participantes, o ator e o alvo. A ação pode ser ainda bidirecional, no qual o participante é ator e alvo da ação.

O segundo diz respeito ao processo de reação, o vetor é formado pela direção do olhar de um ou mais participantes representados. É chamado de reator aquele participante que olha, podendo ser um ser humano, animal, ou qualquer objeto, desde que tenha olhos e seja capaz de expressão facial, e de fenômeno aquilo para que ou aquele para quem se está olhando. Também pode ser transacional ou não transacional. Na primeira, o olhar do participante dirige-se ao fenômeno que, por sinal, está na imagem. Na segunda, o olhar é direcionado para algo fora da imagem. Como não há o fenômeno, temos que imaginar para quem o participante está olhando.

O terceiro é o processo verbal e mental que é muito comum nas histórias em quadrinhos. São dizeres representados por balões. Assim, temos como participantes o dizente, participante do qual emana o balão que indica a fala, e o enunciado, conteúdo inserido no balão. Contudo, se o processo for definido por um balão indicativo de pensamento, os participantes são o experienciador, aquele de quem parte o balão, e fenômeno, o que está inserido no balão.

O penúltimo processo, de conversão, envolve uma mudança de status do participante, o retransmissor, que é ao mesmo tempo alvo de uma ação e ator de outra. 
Esse tipo de estrutura visual é típico de diagramas que representam eventos naturais, como ciclo da água, metamorfose dos anfíbios, mas também pode ser aplicado em (inter)ações humanas.

Por fim, temos o processo de simbolismo geométrico. Nele, há somente o vetor, indicando direcionalidade, por meio de um sinal de infinito, em vez de uma seta.

Em relação às imagens narrativas, Kress e van Leeuwen (2006) ainda explicam que essas podem conter participantes secundários que se relacionam com os participantes principais, mas não por meio de vetores, mas de outras formas. Os autores referem-se a eles como circunstâncias e podem ser de três tipos: (i) de lugar - consiste no contraste entre primeiro e segundo plano; (ii) de meio - nesse caso, não há um vetor nítido entre a ferramenta e o seu usuário; e (iii) de acompanhamento - também não há vetor, o participante estar "com" o outro.

Padrões conceituais estão correlacionados aos processos relacional e existencial do modo verbal. Ocorrem visualmente quando os participantes representados se relacionam em termos de sua classe, estrutura ou significado. Imagens conceituais apresentam três tipos diferentes de processos: (i) classificacional - os participantes se relacionam em termos de taxionomia (implícita ou explícita). Um participante pode fazer o papel de subordinado e outro de subordinante. Há ainda os participantes intermediários. Na taxionomia implícita, os participantes subordinados são distribuídos sime- tricamente no espaço da imagem, em distância e tamanho iguais e orientados para os eixos vertical e/ou horizontal. O subordinante tem a possibilidade de ser inferido pela semelhança ou pelo motivo de estarem agrupados. Na taxionomia explícita, um participante subordinante é ligado a dois ou mais participantes subordinados através de uma estrutura de árvore. O subordinante é colocado acima ou abaixo dos subordinados. Cabe ressaltar que os participantes podem ser realizados verbalmente ou visualmente, ou em ambos, mas, o processo é sempre visual. (ii) Analítico: os participantes se relacionam em termos de uma estrutura de parte-todo, um deles o portador, o todo, e o outro o atributo, a parte. Pode acontecer de aparecer setas, mas que não são vetores, elas apenas realizam uma identidade entre verbal e visual. $\mathrm{O}$ processo analítico pode ser não-estrutural, temporal, exaustivo e inclusivo, topográfico e topológico e espaço-temporal. (iii) Simbólico: diz respeito ao que um participante significa ou é. Pode ser atributivo, quando a identidade de um participante (portador) é estabelecida na relação com outro participante (atributo), ou o sugestivo, quando o participante representa a própria identidade.

De acordo com Kress e van Leeuwen (2006), o modo imagético possui outros recursos para desempenhar outra metafunção, a interpessoal, que diz respeito à interação entre os participantes interativos (produtor da imagem e seu observador) e participantes representa- 
dos, através dos seguintes recursos: (i) olhar - os olhos podem ou não formar vetores. Quando há esse vetor de olhar, dizemos que o participante representado estabelece um contato pessoal com o observador, demandando-lhe algo. Já nas imagens de contato indireto, impessoal, o participante representado não olha para o observador, não há vetor de olhar. O participante representado é oferecido como um item de informação, um objeto de contemplação. (ii) Enquadramento: quando o participante é representado do ombro para cima, ou apenas seu rosto, então, dizemos que a distância social entre ele e o observador é perto e, por isso, sugere intimidade entre os dois. A distância social será média, quando o participante for mostrado da cintura para cima. E longe, quando o participante for retratadode corpo inteiro, inclusive, mostrando o cenário a sua volta. (iii) Perspectiva: a presença de perspectiva indica uma atitude subjetiva, enquanto sua ausência, objetividade. (iv) Ângulo horizontal: quando o plano for frontal, isto é, produtor e participante representados estão de frente, isso sugere envolvimento com o observador. Mas, se o ângulo for oblíquo, isto é, produtor e participante representado não estiverem de frente, isso sugere imparcialidade. (v) ângulo vertical: se o participante for mostrado de um ângulo elevado, ele é posto como pequeno e insignificante em relação ao observador, conferindo poder a esse último. Se a altura dos olhos do participante representado estiver nive- lada a do observador, temos um poder simétrico, uma igualdade entre os dois. Mas, se o participante representado é mostrado de um ângulo inferior/baixo, será visto como imponente e temível, conferindo-lhe poder.

Kress e van Leeuwen (2006) descrevem também como a composição relaciona os elementos representados e interativos da imagem, formando um todo significativo, a partir dos sistemas de: valor da informação, saliência e moldura. Esses três são aplicáveis não somente a imagem, mas, ao texto multimodal, por exemplo, a imagem interagindo com outros modos.

O valor da informação está relacionado ao grau de importância atribuído aos elementos representados, a partir da posição que ocupam na imagem. Eles podem ser polarizados na horizontal, na vertical ou centralizados. Nesse sentido, os elementos são analisados em termos de: (i) dado e novo - informações posicionadas à direita são tidas como o ponto de partida da mensagem, o senso comum, aquilo que é passivo, enquanto aquelas posicionadas à esquerda dizem respeito àquilo que se quer atenção especial, ao que é novo, ou problemático; (ii) ideal e real - informações localizadas na parte superior representam sempre um ideal, já aquelas na parte inferior, aquilo que é concreto, tido como verdadeiro e também informações mais especificas; (iii) centro e margem - elementos no centro são geralmente aqueles que são o núcleo da informação, já os que estão na margem 
possuem um valor subserviente e dependem do elemento central.

A saliência é responsável por criar uma hierarquia de importância entre os elementos, selecionando alguns como os mais importantes e mais dignos de atenção que outros. Isso ocorre através do contraste de tamanho entre os participantes representados, e também se eles estão em primeiro ou segundo plano, pela cor.

A moldura são elementos que podem ser representados como identidades separadas ou que se relacionam. Tal desconexão entre os elementos acontece por meio de linhas divisórias, descontinuidade no uso de cor ou forma, espaços vazios, por outro lado, a conexão se dá pela ausência de espaços vazios e de linhas divisórias, por cores e forma que se mantêm e se repetem no todo da composição. A moldura é um princípio multimodal realizado por diferentes recursos em diferentes modos semióticos. Por exemplo, no interior de espaços e prédios, as molduras podem ser divisórias, que vão desde cortinas e telas frágeis até a paredes sólidas, segregando espaços e, portanto, as pessoas, grupos e/ou atividades que estão ou são desenvolvidas neles.

Kress e van Leeuwen (2006) tratam ainda da modalidade. Ela se refere a como uma imagem pode ter maior ou menor grau de verdade e credibilidade. $\mathrm{O}$ critério dominante para o que é real ou não é a aparência das coisas, no quanto de correspondência há entre o que vemos normalmente em um objeto e o que ve- mos na representação visual. Os autores apontam oito marcadores de modalidade: a saturação da cor, diferenciação da cor, modulação da cor, contextualização, representação, profundidade, iluminação e brilho.

\section{A imagem em movimento}

Os padrões representacionais, interativos e composicionais que discutimos no subtópico anterior também se aplicam à imagem em movimento. No entanto, há algumas diferenças no tratamento deste material, por causa do movimento.

A primeira diferença destacada por Kress e van Leeuwen (2006) é em relação aos processos narrativos. Segundo eles, o vetor é realizado pelo movimento dos participantes representados. Além disso, a relação entre ator e alvo pode ser representada em uma única cena, na qual, são mostrados o ator e o alvo, ou em duas subsequentes cenas, a primeira mostrando $o$ ator e a segunda o participante alvo (ou vice-versa). Essa desconexão fílmica mostra os participantes como indivíduos isolados, mesmo quando eles estão interagindo com os outros, o que pode desconectar os atores dos participantes alvos e de suas ações, e do efeito de suas ações sobre esses participantes. Para Kress e van Leeuwen (2006), muitas vezes, esse processo de edição das imagens permitem a "dissimulação" dos fatos. A imagem em movimento realiza, ainda, eventos que não têm nem um ator e nem um alvo.

A escolha entre conexão e desconexão entre os participantes também existe nos 
processos de reação. Os filmes podem mostrar reator e fenômenos em uma mesma cena, ou em cenas subsequentes. Reações desconexas têm uma sensação muito subjetiva, de "primeira pessoa", pois é como se o participante interativo, o observador, estivesse olhando para o fenômeno "através dos olhos do reator".

Finalmente, enquanto as imagens ainda desenvolvem balões de diálogo para realizar processos verbais, nas imagens em movimento, o diálogo não é representado visualmente, através da escrita, mas diretamente, por meio da fala. A sincronização entre a fala e os movimentos labiais do participante substitui o vetor que liga o dizente e $o$ enunciado. Sem essa sincronização, as imagens em movimento não significam que o enunciado que ouvimos é realmente falado pelo dizente que vemos. Isso ocorre quando o observador ouve o enunciado, enquanto assiste a reação do outro participante da interação.

A segunda diferença diz respeito à dimensão interativa, na qual se observa como as posições da câmera criam relações simbólicas entre os observadores e o que é retratado em uma imagem. No caso da imagem em movimento esse relacionamento torna-se dinâmico. A câmera pode captar os participantes de um ângulo frontal, alto ou baixo, ou com um zoom mais próximo ou longe. Mesmo com a câmera parada, os participantes podem mover-se em direção a ela, ou descer e subir escadas, com a inclinação da câmera para cima ou para baixo para segui-los, alterando assim o ângulo que os observadores veem os participantes. Em geral, a imagem em movimento representa as relações sociais como dinâmicas, flexíveis e mutáveis. Distância e ângulo podem ser dinamizados de duas formas: com os participantes representados iniciando a mudança, ou com os produtores da imagem. No primeiro caso, a atitude é objetiva, é como se tudo estivesse sendo gravado da maneira como está ocorrendo, e no segundo, subjetiva.

A distinção entre oferta e demanda também se aplica à imagem em movimento, as quais são dinamicizadas à medida em que os participantes representados podem virar-se para a câmera e olhar para a lente (e, consequentemente, para o observador), ou podem evitar seu olhar.

O conceito de modalidade também é aplicável à imagem em movimento. Nesse caso, o movimento também será considerado um marcador de modalidade,representando diferentes graus de realismo ou de abstração ${ }^{10}$.

Por fim, diferenças são observadas no que diz respeito à composição. Aqui, também valor da informação, saliência e moldura ganham mais dinamicidade. Algo que começa como dado pode se mover para a posição do novo, ou algo que tem pouca relevância pode tornar-se altamente saliente em uma cena, por exemplo, ao se mover para a luz, ou por uma mudança de foco da câmara. Participantes que se localizam em espaços diferentes, significando uma falta de comunicação entre eles, podem mover-se 
para o espaço um do outro, desfazendo a moldura entre eles.

Kress e van Leeuwen (2006) ressaltam que a imagem em movimento, o filme, por exemplo, é caracteristicamente multimodal, envolvendo não somente o visual, mas também a voz, o som e a música. Porém, esses pressupostos da GDV são possíveis de serem aplicados a aspectos espaciais da imagem em movimento.

\section{O software ELAN}

Para a seleção e análise dos dados, utilizamos o software Eudico Linguistic Annotator, mais conhecido pela sigla ELAN $^{11}$, desenvolvido na Holanda pelo Instituto de Psicolinguística Max Planck. Essa ferramenta permite a criação, edição, visualização e anotação de imagens em movimento e áudio.

Apesar de o ELAN fornecer muitos recursos digitais de anotações, utilizamo-lo somente para assistir ao vídeo Carrossel,para selecionar e recortar as cenas em que recursos multimodais foram utilizados pelos produtores dessa campanha a fim de criar certos significados. Isso porque, por meio dessa ferramenta, visualizamos o movimento das imagens em centésimos de segundos, e, desse modo, identificamos com mais precisão o momento em que os recursos - tais como os gestos, por exemplo - são realizados.

As cenas analisadas no tópico seguinte encontram-se reproduzidas e enumeradas nos anexos.
Análise da imagem em movimentos e outros recursos semióticos do vídeo da propaganda Carrossel

O vídeo da campanha Carrossel tem duração de dois minutos e quatro segundos, e nele, vários modos se articulam na criação de um todo significativo, como a imagem em movimento, a linguagem verbal (escrita) e a trilha sonora. Anexa a este artigo, encontra-se a imagem estática das cenas que foram analisadas, as quais estão enumeradas para melhor identificação.

O vídeo dessa campanha inicia com a câmera focalizando de perto algumas lâmpadas (cenas 1 e 2). Nas cenas seguintes, em um plano um pouco mais aberto e de um ângulo oblíquo, a câmera captura novamente as lâmpadas e parte de um cavalo (cenas 3,4, 5 e 7), e, depois, algo que não é possível identificar muito bem do que se trata (cenas 6 e 8). As imagens são todas em preto e branco, ou seja, há ausência de cor, há momentos em que a iluminação é mais escura (cenas 1, 3 e 4) e outros em que ela é mais clara (cenas 2,5,6,7 e 8). Apesar das lâmpadas e do cavalo estarem em movimento, o que por si só é um vetor de ação, podemos, de acordo com Kress e van Leeuwen (2006), descrever essas cenas como formando um processo conceitual analítico, pois a câmera focaliza partes do todo que é o brinquedo carrossel. 
Não há texto verbal nessa parte do vídeo, porém, as imagens interagem com a trilha sonora, que conforme Kress (2011), também pode ser considerada um modo. Assim, constroem-se novos sentidos, a partir dessa interação entre as imagens e a trilha sonora da música Fake Plastic Trees, da banda Radiohead, cuja letra faz uma crítica contra o mundo de aparências. Mais especificamente, nessas oito primeiras cenas, ouvimos o som da guitarra e da bateria em um volume mais baixo e lento, e duas vezes o verso It wears her out.

Depois de vinte e um segundos, o som da música acelera, e aparece a cena de duas crianças montadas em cavalos de um carrossel (9). Os primeiros versos da segunda estrofe são cantados ${ }^{12 .}$

Como esses dois participantes não olham diretamente para câmera, de acordo a GDV de Kress e van Leeuwen (2006), o contato estabelecido entre participante e observador é de oferta, ou seja, são apresentados como objetos de contemplação. Eles foram filmados em meio à ação de brincar. Importante ressaltar que a câmera não se movimenta, é como se tudo estivesse sendo gravado da maneira como está ocorrendo, de modo objetivo.

Apesar da ausência de olhar, é estabelecida uma relação de envolvimento entre esses participantes e o observador, por meio das expressões faciais, já que eles sorriem, e também pelos recursos de enquadramento e de ângulo. As duas crianças são focalizadas pela câmera da cintura para cima, em uma distância social perto, sugerindo, como descrevem Kress e van Leeuwen (2006), intimidade com o observador. Há também uma relação de envolvimento entre participantes representados e interativos, pois, de acordo com esses dois autores (2006), tem-se esse significado quando o plano é frontal; e também, igualdade de poder entre esses dois participantes e o observador, quando o ângulo vertical é da altura dos olhos.

De acordo com a metafunção ideacional descrita na GDV, os processos são narrativos de ação e de reação. Observamos vetores de ação no movimento dos braços, cabeça e troco dos participantes, por exemplo, nas cenas (15), (16), (18), (17), (20), (24), (25), (26), (31) e (32). No entanto, não há uma meta. São processos de ação não transacionais. Traduzindo para a linguagem verbal, podemos dizer que as duas crianças brincam, se divertem. Aos 47 segundos do vídeo, o som da música torna-se mais acelerado, quando temos a imagem do participante da direita sacudindo os braços (cena 18), como se tivesse em êxtase com aquele barulho da guitarra. É apresentada a terceira estrofe da música. ${ }^{13}$ Há vetores também que partem dos olhos dos participantes. Ora eles olham para um fenômeno que não aparece na cena (processo de reação não transacional), por exemplo, cena (16), ora um dos participantes olha o outro (processo de reação transacional), como nas cenas (13) e (19). Há um momento no vídeo, cena (39), em que os dois parecem olhar um para o outro (processo de reação bidirecional). 
Muito importante para o sentido da mensagem é a composição dos elementos. Em relação à imagem em movimento, os dois participantes são polarizados na horizontal, o que nos leva a analisá-los em termos de dado e novo, de acordo com Kress e van Leeuwen (2006). O participante portador da Síndrome de Down localiza-se à direita que é o local da informação de atenção especial e problemática. O outro participante é localizado à esquerda, espaço que geralmente traz uma informação familiar.

Ambos são bem iluminados e destacam-se na cena, uma vez que quase não conseguimos visualizar a paisagem no fundo, a qual está bem embaçada. Porém, como veremos adiante, o movimento do cavalo de subir e descer permite que um participante ganhe mais saliência (KRESS; VAN LEEUWEN, 2006) que o outro em algumas cenas.

Os participantes, a princípio, estão conectados, pois aparecem na mesma cena como se estivessem brincando juntos. Simultaneamente, com essa imagem em movimento, aparece o texto escrito que em geral são orações estruturadas em períodos simples. As nove primeiras orações surgem na parte inferior da tela (real), logo abaixo da imagem, com um efeito lento de "aparecer". São informações específicas que apresentam os participantes da cena, em termos do que fazem e do que são, de acordo com Halliday e Matthiessen (2004). Desse modo, texto e imagem não se sobrepõem, ou seja, esses dois elementos estão desco- nectados na composição, segundo Kress e van Leeuwen (2006).

Em relação à tipografia, também descrita como um modo semiótico por van Leeuwen 2006b, as letras possuem tamanho pequeno, apresentam uma curvatura (arredondamento) e cor branca, contrastando com o fundo preto em que aparecem. Abaixo, transcrevemos essas orações e o tempo em que aparecem no vídeo.

a) Carlinhos vai à escola todos os dias. $(00: 32,29)$

b) O amigo dele, não. (00:36,62)

c) Carlinhos faz natação todos os dias. (00:49,71)

d) O amigo dele, não. (00:53,94)

e) Carlinhos tem aulas de piano. $(01: 06,91)$

f) O amigo dele, não. (01:11,27)

g) $\mathrm{Ei},(01: 25,71)$ este é o Carlinhos. $(01: 29,37)$

h) E este é o amigo dele. (01:35,29)

i) Ele é um menino de rua. $(01: 42,38)$

Conforme Halliday e Matthiessen (2004), as quatro primeiras orações representam a vida dos participantes, visualizados na cena, em termos do que esses fazem. Observe que, nas orações (a) e (c), "ir" e "fazer" são processos materiais, cujo ator é "Carlinhos". Essas duas orações trazem a informação da frequência que essas ações ocorrem, "todos os dias", circunstância de localização temporal.

As duas orações que se seguem (e) e (f), na análise que Halliday e Matthiessen (2004) fazem dos processos, representam os participantes em termos do que 
possuem, uma vez que em (e) podemos identificar o processo relacional possessivo atributivo "ter", cujo possuidor é "Carinhos" e o possuído, "aulas de piano".

Nas orações (b), (d) e (f), as quais dizem respeito ao amigo de Carlinhos, temos a elipse do processo material e relacional, e a presença do advérbio de negação "não", indicando assim que esse participante, que não é referido pelo nome, mas, pela expressão nominal "o amigo dele", não tem acesso à educação, ao esporte e a arte, portanto, o participante é excluído de tudo o que é direito de uma criança.

Porém, não fazemos a interpretação desse modo isoladamente, mas atribuímos sentido ao que lemos a partir do que vemos na imagem, e vice e versa. Quando esse texto é apresentado, buscamos identificar os referente de "Carlinhos" e "o amigo dele" na imagem. A tendência é associarmos, por vários fatores, Carlinhos ao participante da esquerda e "o amigo dele" ao participante da direita. Primeiro, porque os portadores da Síndrome de Down são vistos pela sociedade como incapazes de exercerem certas atividades, $\mathrm{e}$, além disso, são poucos os que frequentam escola regular. Segundo, porque nossa leitura é orientada da esquerda para direita, do dado para o novo (HALLIDAY; MATTHIESSEN, 2004, KRESS; vAN LEEUWEN, 2006). As informações apresentadas inicialmente são as do Carlinhos, portanto, o dado. Como vimos, o dado é o local da informação familiar, logo o que é comum na nossa sociedade é uma criança que não é portadora da Síndrome de Down ir à escola, fazer natação e ter aulas de piano, o contrário, seria uma informação não esperada, nova. Além disso, quem ocupa a posição de dado na imagem é o participante visto como uma "criança normal" e no novo, o participante portador da Síndrome de Down. Terceiro, pelos gestos do participante da direita no momento em que o texto aparece na tela. Quando as orações (f) e (g), referentes a Carlinhos, começam a surgir, o participante com Síndrome de Down vira o rosto e olha para o participante da esquerda (cenas 13 e 19). Mas, quando surge a oração (b), sobre o amigo de Carlinhos, ele inclina a cabeça e olha para baixo (cena 14). Também no momento em que a oração (d) aparece, o participante com Síndrome de Down é o que está em maior saliência na cena, pois, o seu cavalo sobe, enquanto o do outro participante, desce, fazendo com que aquele apareça mais que esse (cena 21). Além disso, ele está com os braços bem abertos e rindo, ou seja, numa interação maior com o observador.

O momento ápice do vídeo é quando aparece a interjeição "ei”, responsável por estabelece um contato direto com o observador/leitor, chamando sua atenção para o fato de que ele, talvez, tenha feito um julgamento preconceituoso, deduzindo que o amigo de Carlinhos seria o personagem da direita. ${ }^{14}$ Então, a câmera focaliza o rosto do participante da direita, o portador de Síndrome de Down (cena 34), e depois, do participante da esquerda (cena 35). Portanto, a 
distância social é próxima, o que sugere maior intimidade entre participantes representados e interativos. Como as duas crianças são mostradas em cenas distintas, dizemos que essas estão desconectadas. Cada uma é mostrada individualmente. Na imagem, temos um processo conceitual simbólico (KRESS; vAN LEEUWEN, 2006), e, no verbal, um processo relacional identificativo (HALLIDAY; MATTHIESSEN, 2004). Aqui, participantes são representados em termos do que são.

$\mathrm{Na}$ última cena, a câmera focaliza apenas os pés do participante da esquerda que estão calçados com uma chinela de borracha (cena 36). Para Kress e van Leeuwen (2006), nesse tipo de imagem, por não se ver o olhar do participante, não há contato social, o que pode significar uma exclusão do participante da sociedade. Conforme a GDV desses dois autores (2006), o processo é simbólico atributivo, pois, o atributo possuído, a chinela, identifica o participante da esquerda como "menino de rua", expressão utilizada no "verbal". Nessa parte, a música fica novamente mais baixa, como no início, e é cantado apenas o verso do refrão It wears me out.

Depois que a imagem em movimento termina, a tela escurece, e no centro, duas outras orações aparecem, uma embaixo da outra.

j) Milhares de crianças no Brasil $(01: 50,65)$ precisam de sua ajuda. (01:51,92)

k) Os portadores da Síndrome de Down $(01: 52,30)$ só precisam do seu respeito. $(01: 53,25)$
Essa mensagem fica estática por um tempo e, em seguida, desaparece. A tela fica escura e aparece essa mensagem final:

l) DOWN. (01:59,93)

m) A pior síndrome é a do preconceito. (02:01,28)

\section{Considerações finais}

Neste artigo, discutimos que as pessoas expressam sentidos através da seleção de recursos semióticos que consideram mais adequados para a comunicação e representação. Portanto, a partir dessa série de escolhas realizadas na produção do vídeo da propaganda Carrossel, escolhas que são politicamente orientadas, o Instituto MetaSocial questiona a representação do que é "criança normal", fazendo com que os observadores tomem consciência de que o portador da Síndrome de Down tem capacidades para realizar quaisquer atividades.

"Carlinhos", o participante com Síndrome de Down, possui uma vida como a de quase todas as crianças da idade dele, pois, como apresenta o vídeo, "milhares de crianças no Brasil” são como "o amigo dele", um "menino de rua". A propaganda, ao trazer um participante que representa aqueles que estão na rua, leva-nos a refletir que são fatores sociais, como a pobreza, que impossibilitam as pessoas de frequentar escola, ter acesso a atividades de artes, cultura e esportes, e não alguma diferença biológica que a pessoa possa ter. 
A propaganda nega o discurso sobre o portador da Síndrome de Down como aquele "indivíduo dependente", ou seja, que necessita da ajuda de outras pessoas para realizar algumas atividades. Ao contrário, coloca o portador da Síndrome de Down, o Carlinhos, como ator dos processos, tanto no modo verbal quanto no visual. Para o Instituto MetaSocial aqueles que precisam de "ajuda" não são os portadores da Síndrome de Down, mas as pessoas que não possuem condição econômica.

A propaganda faz ainda uma crítica à sociedade preconceituosa. A escolha da trilha sonora vai ao encontro desse propósito, pois a música Fake Plastic Trees fala de um mundo em que tudo é um "falso plástico" como, por exemplo, as flores de plástico, que não são reais, mas, artificiais. Desse modo, pessoas "perfeitas" não existem, então, porque não respeitar as diferenças? As demais propagandas dessa campanha de inclusão social do Instituto MetaSocial, produzidas depois do vídeo do Carrossel, com exceção de Garçonete, exploram mais esse aspecto que diz respeito a diversidade.

Finalmente, os resultados obtidos nessa análise permitem-nos, então, afirmar que o letramento esta relacionado com diferentes práticas e habilidades, e envolve outros modos de significado, além do puramente linguístico. Assim, para que o sujeito seja capaz de consumir (ler) de forma mais crítica os discursos que circulam nos variados gêneros discursivos e produzir mensagens que explorem todo o potencial semiótico que tem a sua disposição, é necessário um letramento multimodal. $\mathrm{Na}$ análise realizada da propaganda Carrossel, somente chegamos a essas considerações acerca do discurso e identidade do Portador de Síndrome de Down, porque consideramos todos os modos envolvidos na produção do sentido. Então, não basta apenas que na sala de aula se estude diversos gêneros discursivos, mas, é preciso oferecer aos alunos categorias que possibilitem que eles analisem os significados produzidos pelos recursos semióticos de diferentes modos, como é a proposta da teoria da multimodalidade.

\section{Multimodality and literacy:} analyzing of Carousel advertisement

\section{Abstract}

In this article, we analyze the semiotic resources of Carousel advertisement of a campaign for social inclusion of the carrier of Down syndrome by Institute of MetaSocial. This advertisement was publicized in television media in 1998, during the commercial breaks of Rede Globo. For this, we base our analysis on Multimodal Theory and Social Semiotic, specifically in the work of Kress (2010), Kress and van Leeuwen (2001, 2006), van Leeuwen (2005, 2006, 2006b) and Street, Pahl and Rowsell (2011) through which we describe and interpret the semiotic resources used in the video and the relationship of the moving image with other modes in which it interacts to create the identity of the carrier of 
Down Syndrome as a "normal" person who should be respected, consequently emphasizing the increasingly urgent necessity of a multimodal literacies to the comprehension and learning of various discourse genres.

Keywords: Social semiotic. Multimodal. Literacy. Advertisement.

\section{Notas}

1 BARTHES, Roland. Image, music, text. London: Fontana Press, 1977.

2 Nossa tradução de "the use of several semiotic modes in the design of a semiotic product or event, together with particular way in which these modes are combined - they may for instance reinforce each other (say the same thing in different ways), fulfill complementary roles".

3 Nossa tradução de "multimodality describes approaches that understand communication and representation to be more than about language, and which attend to the full range of comunicacional forms people use - image, gesture, posture, - and the relationships between them".

4 Nossa tradução de "any instance of language, in any medium, that makes sense to someone who knows the language".

5 Halliday e Matthiessen (2004) utilizam "oração", por que analisam essas metafunções em relação à linguagem verbal.

6 Nossa tradução de "opened the door for multimodality and laid the groundwork for extending and adapting social semiotics across a range of modes".

7 Nossa tradução de: "[...] as the actions and artifacts we use to communicate, whether they are produced physiologically - with our vocal apparatus; with the muscles we use to create facial expressions and gestures, etc. - or by means of technologies - with pen, ink and paper; with computer hardware and software; with fabrics, scissors and sewing machines, etc".

8 Disponível em: <http://www.metasocial.org.br>. Acesso em: 25 jun. 2013.

9 Disponível em: <http://www.movimentodown. org.br/2013/01/nova-campanha-do-instituto-meta-social-convida-o-publico-a-soltar-a-voz-para-celebrar-as-diferencas/>. Acesso em: 25 jun. 2013.
10 Kress e van Leeuwen (2006) chamam atenção para razões pragmáticas, como o orçamento e tempo para produção dos filmes que podem interferir, por exemplo, na construção do cenário, o que, consequentemente, pode reduzir o naturalismo.

11 O programa encontra-se disponível para download gratuito através do site http://www. lat-mpi.eu/tools/elan/

12 She lives with a broken man/ A cracked polystyrene man/ Who just crumbles and burns

13 She looks like the real thing / She tastes like the real thing / My fake plastic love / But I can't help the feeling / I could blow through the ceiling / If I just turn and run.

14 Não somente nesse, como também em outros vídeos, Garçonete e Adolescente, a maneira como as imagens são apresentadas parece sugerir que o observador as interprete de uma forma, enquanto, na verdade, o sentido é outro.

\section{Referências}

BAKHTIN, Michael (1992). Estética da criação verbal. 3. ed. São Paulo: Martins Fontes, 2000.

BRASIL. Parâmetros curriculares nacionais: ensino médio. Brasília: MEC, 1999.

BRASIL. Orientações pedagógicas. Brasília: MEC, 2009. Disponível em: <http:// crv.educacao.mg.gov.br/SISTEMA_CRV/ index.aspx?ID_OBJETO $=102400 \&$ tipo $=0$ $\mathrm{b} \& \mathrm{cp}=000099 \& \mathrm{cb}=\& \mathrm{n} 1=\& \mathrm{n} 2=$ Orientações Pedagógicas\&n3=Ensino Médio\&n4=Língua Portuguesa\&b=s>. Acesso em: 28 ago. 2012.

JEWITT, Carey. An introduction to multimodality. In: JEWITT, Carey (Org.). The Routledge handbook of multimodal analysis. Londres e Nova York: Routledge, 2011. p. 191-200.

Different approaches to multimodality. In: JEWITT, Carey (Org.). The Routledge handbook of multimodal analysis. Londres e Nova York: Routledge, 2011. p. 191-200.

HALLIDAY, Michael; MATTHIESSEN, Christian. An introduction to functional grammar. 3. ed. London: Hodder Arnold, 2004. 
KRESS, Gunther. Multimodality: a social semiotic approach to contemporary communication. London e Nova York: Routledge, 2010. p. 1- 31 .

. What is mode? In: JEWITT, Carey (Org.). The Routledge handbook of multimodal analysis. Londres e Nova York: Routledge, 2011. p. 191-200.

KRESS, Gunther; VAN LEEUWEN, Theo (1996). Reading images: the grammar of visual design. 2. ed. London: Routledge, 2006.

Introduction. In: KRESS, Gunther; VAN LEEUWEN, Theo. Multimodal discourse: the modes and media of contemporary communication. Londres: Oxford University. Press Inc, 2001.

SANT'ANNA, Armando. Propaganda: teoria, técnica e prática. São Paulo: Pioneira, 1998.

SEVERO, Susan Severo de. Enem: um olhar para a leitura. 2010. Trabalho de conclusão de curso. 52 p. (Licenciatura em Letras) Instituto de Letras, Departamento de Letras Clássicas e Vernáculas, Universidade Fede- ral do Rio Grande do Sul, Porto Alegre, 2010. Disponível em: <http://www.lume.ufrgs.br/ bitstream/handle/10183/26399/000758275. pdf?sequence=1>. Acesso em: 20 jul. 2012 .

SOARES, M. Letramento: um tema em três gêneros. Belo Horizonte: Autêntica, 1998.

STREET, Brian; PAHL, Kate; ROWSELL, Jennifer. Multimodality and new literacy studies. In: JEWITT, Carey (Org.). The Routledge handbook of multimodal analysis. Londres e Nova York: Routledge, 2011. p. 191-200.

VAN LEEUWEN, Theo. Multimodality, genre and design. In: NORRIS, Sigrid; JONES, Rodney. Discourse in action: introducing mediated discourse analysis. New York: Routledge, 2005.

. Introducing social semiotics. Nova York: Routledge, 2006a.

Towards a semiotics of typography.

Information Design Journal \& Document Design, v. 14, n. 2, p. 139-155, 2006b.

\section{Anexo}
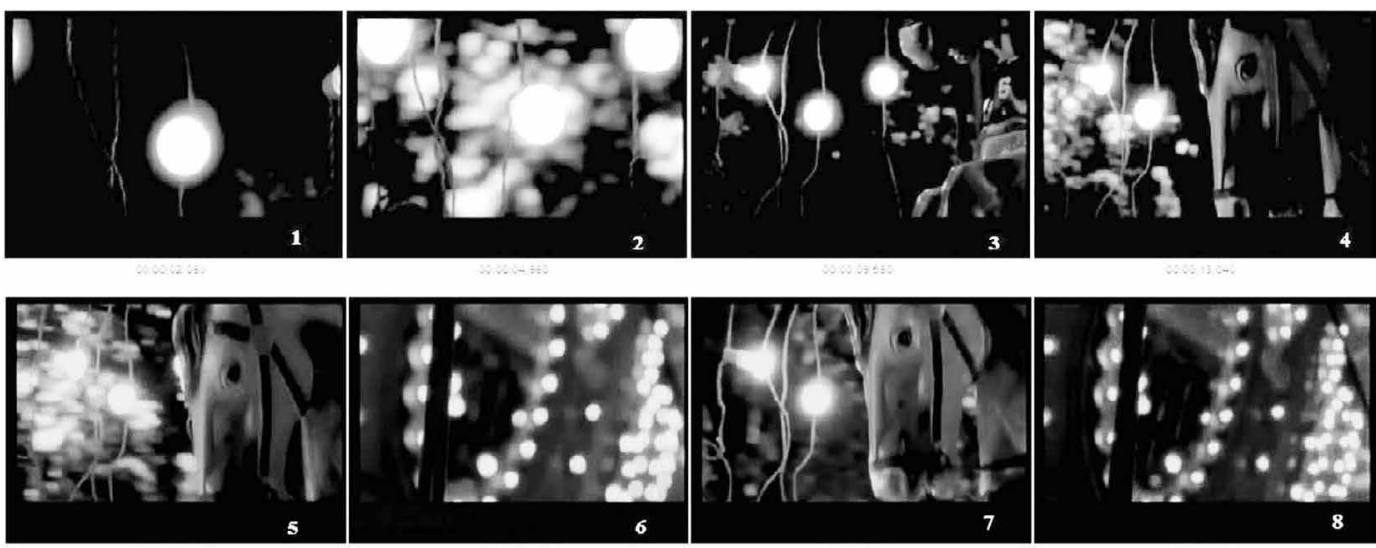

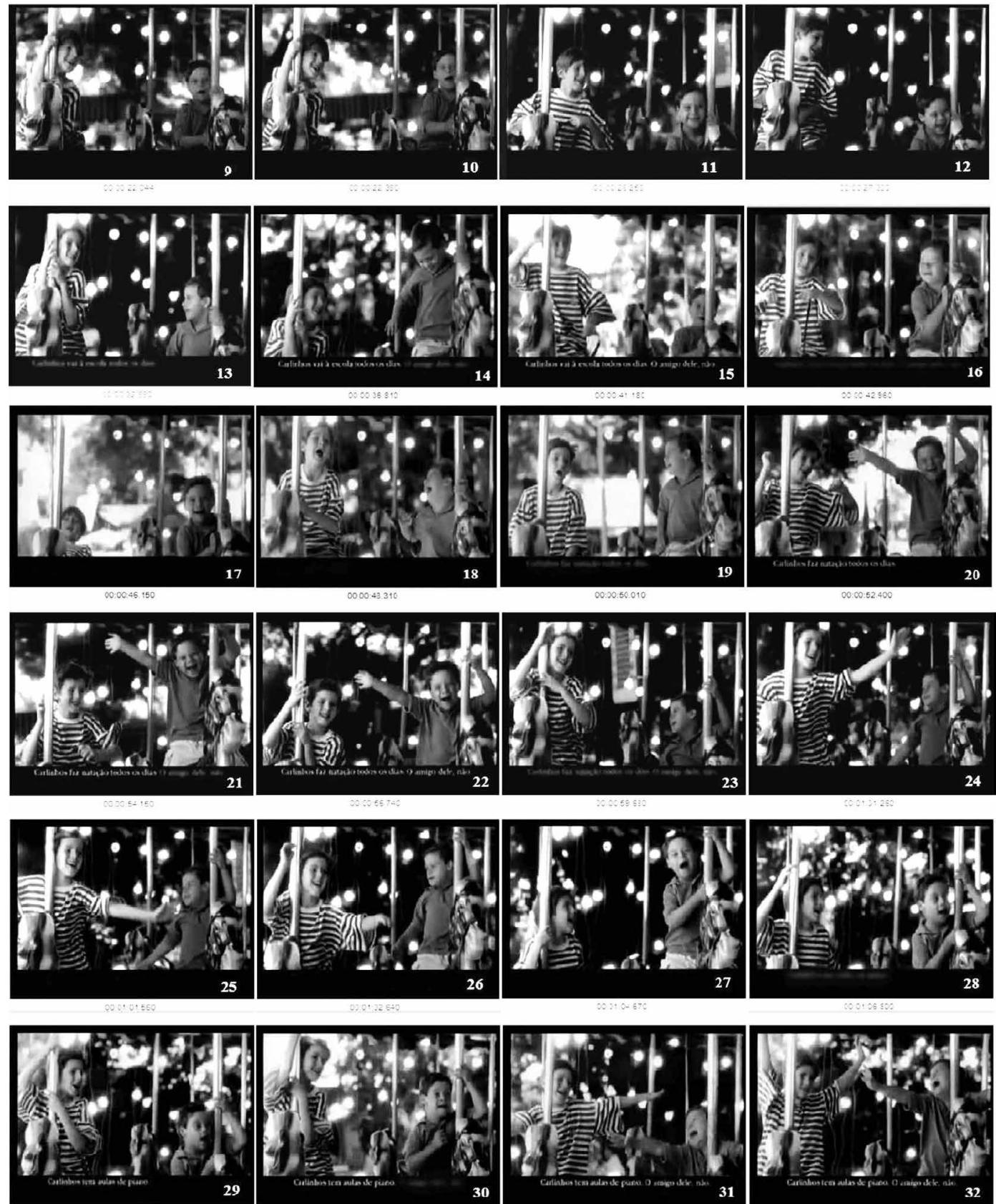

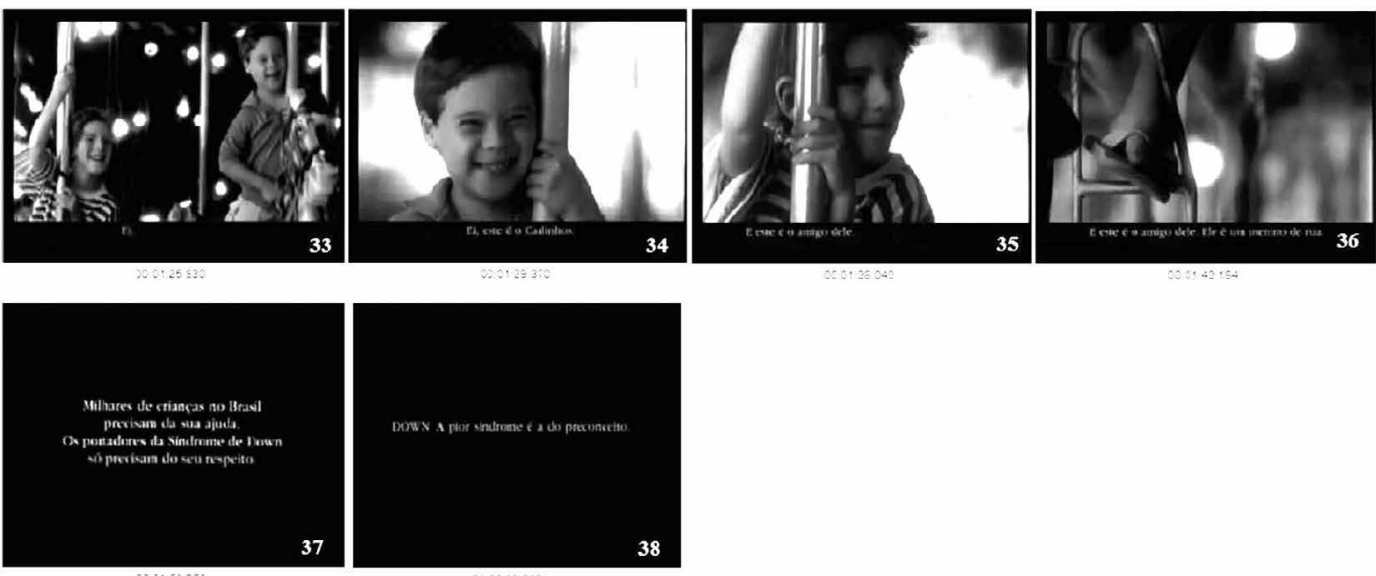

Cenas recortadas do vídeo Carrossel. Disponível em: http://www.metasocial.org.br/\#!campanhas-e-vdeos/c236o. Acesso em: 28 ago. 2012. 